\title{
Mainstream Smoke Gas Phase Filtration Performance of Adsorption Materials Evaluated With A Puff-by-Puff Multiplex GC-MS Method*
}

\author{
by \\ Lixin Xue, Charles E. Thomas, and Kent B. Koller \\ Philip Morris USA, P.O. Box 26583, Richmond, VA 23261, USA.
}

\section{SUMMARY}

The mainstream smoke filtration performance of activated carbon, silica gel and polymeric aromatic resins for gasphase components was evaluated using a puff-by-puff multiplex gas chromatography-mass spectrometry (GCMS) analysis method (1). The sample 1R4F Kentucky reference cigarettes were modified by placing the adsorbents in a plug/space/plug filter configuration. Due to differences in surface area and structural characteristics, the adsorbent materials studied showed different levels of filtration activities for the twenty-six constituents monitored. Activated carbon had significant adsorption activity for all the gas-phase smoke constituents observed except ethane and carbon dioxide, while silica gel had significant activities for polar components such as aldehydes, acrolein, ketones, and diacetyl. XAD-16 polyaromatic resins showed varied levels of activity for aromatic compounds, cyclic dienes and ketones. [Beitr. Tabakforsch. Int. 20 (2002) 251-256]

\section{ZUSAMMENFASSUNG}

Anhand einer multiplexen zugweisen gaschromatographischen massenspektrometrischen (GC-MS) Analysemethode wurde die Filtrationsleistung von Aktivkohle, Siliciumgel und polymeren aromatischen Harzen für Gasphasenbestandteile des Hauptstromrauchs untersucht (1). Die 1R4F Kentucky Referenzcigaretten wurden modifiziert, indem die Adsorbentien in eine Filtervorrichtung bestehend aus Filterstöpsel/Zwischenraum/Filterstöpsel in Sandwichmethode eingefügt wurden. Aufgrund der unterschiedlichen Oberflächengröße und Struktur wiesen die verschiedenen Adsorbentien unterschiedlich hohe Filtrationsleistungen für die 26 untersuchten Substanzen auf. Die Filtrationsleistung der Aktivkohle war bei allen Gasphasenbestandteilen des Hauptstromrauchs mit Ausnahme von Ethan und Kohlendioxid signifikant, während Siliciumgel bei den polaren Komponenten, wie beispielsweise den Aldehyden, Akrolein, den Ketonen und Diacethyl eine signifikante Filtrationsleistung aufwies. Die Filtrationsleistung der polyaromatischen der XAD-16 Harze war für aromatische Substanzen, cyclische Diene und Ketone unterschiedlich hoch. [Beitr. Tabakforsch. Int. 20 (2002) 251-256]

\section{RESUME}

La performance de filtration pour la fumée du courant principal du charbon actif, du gel de silice et de résines polymères aromatiques a été évaluée au moyen d'une méthode de chromatographie en phase gazeuse-spectrométrie de masse (GC-MS) multiplex bouffée par bouffée (1). Les cigarettes de référence Kentucky 1R4F ont été modifiées par l'intégration des adsorbants dans une configuration de filtre consistant en bout-filtre/espace/bout-filtre. A cause des différences dans la surface et dans les caractéristiques structurales entre les adsorbants étudiés, les taux de filtration respectifs pour les vingt-six composants dosés sont différents. Le charbon actif démontre une performance de filtration significative pour tous les constituants dosés dans la phase gazeuse du courant principal, sauf pour l'éthane et le dioxide de carbone, tandis que le gel de silice a une efficacité de filtration significative pour les composants polaires comme les aldéhydes, les cétones et le diacetyle. Les résines polyaromatiques XAD-16 démontrent des efficacités de filtration variables pour les composants aromatiques, les diènes cycliques et les cétones. [Beitr. Tabakforsch. Int. 20 (2002) 251-256] 


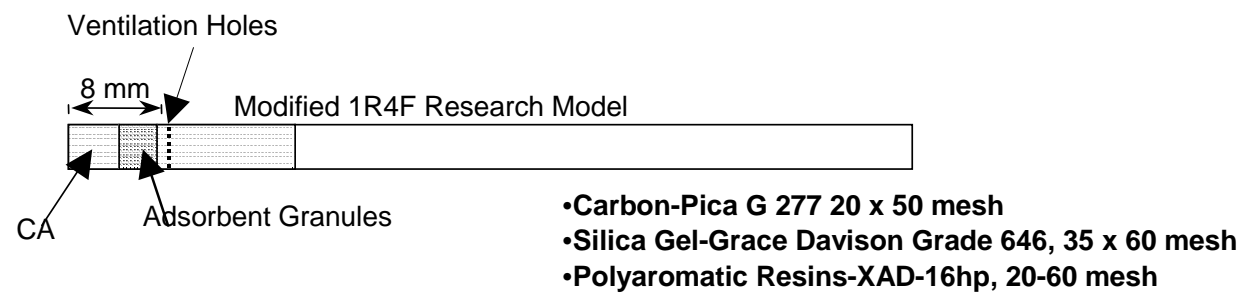

Figure 1. Schematic diagram of the formed PSP type cigarette testing sample

Table 1. Some physical parameters of cigarette samples with PSP adsorbent filters

\begin{tabular}{lccc|cc}
\hline Adsorbent & Carbon & Silicia gel & XAD-16 & 1R4F Average/Sigma \\
\hline RTD $\left(\mathrm{mmH}_{2} \mathrm{O}\right)$ & 155 & 177 & 130 & 140 & 7 \\
Dilution $(\%)$ & 22 & 23 & 24 & 30 & 4 \\
Adsorbent $(\mathrm{mg})$ & 102 & 76 & 102 & 0 & 0 \\
Surface area $\left(\mathrm{m}^{2} / \mathrm{g}\right)$ & -1590 & $275-375$ & 800 & & 0 \\
CA replaced $(\mathrm{mg})$ & -25 & -23 & -15 & 0 & 0 \\
\hline
\end{tabular}

\section{INTRODUCTION}

Mainstream cigarette smoke is a complex dynamic system composed of both particulate phase and volatile phase. Selectively removing gas or semi-volatile components, identified by the public health communities as potentially harmful, from the smoke volatile phase may be an approach to reducing the risk associated with smoking $(2,3,4)$. One promising method for this purpose is to incorporate adsorbents into cigarette filters. One example in current use for producing filters is a cellulose acetate (CA) filled with activated carbon added during the plug making process. However, the use of triacetin in the plug-making process contaminates activated carbon granules. This results in lower filtration activity for smoke gas-phase components. One method to reduce the contamination of adsorbent materials by triacetin is to sandwich them between cellulose acetate plugs in plug/space/plug (PSP) configurations. Using test filters in a PSP configuration, and the recently developed multiplex gas chromatography-mass spectrometry (GC-MS) method, the puff-by-puff filtration performance of various categories of improved, new or existing high surface area adsorbent materials can be rapidly evaluated simultaneously for multiple smoke gas components. In this paper we will report some of our recent results on using PSP filters with activated carbon, silica gel and polyaromatic XAD resins to reduce mainstream cigarette gas-phase components.

\section{EXPERIMENTAL AND PROCEDURES}

\section{Materials and preparation of samples}

All cigarettes tested in this study were either standard 1R4F Kentucky reference cigarettes or test cigarettes consisting of 1R4F cigarettes with modified PSP filters. These were fabricated in the following manner. First the CA filter was removed from a $1 \mathrm{R} 4 \mathrm{~F}$ cigarette leaving the filter overwrap intact. The CA filter was shortened by $8-10 \mathrm{~mm}$ and reinserted into the filter overwrap to become the first "plug" in the PSP filter. Test adsorbent materials were then added, and a second plug of CA was inserted completing the PSP filter. The excess portion of the CA plug was further removed by a razor blade. A schematic diagram of the formed PSP type cigarette testing sample is shown in Figure 1. Note that the included adsorbent materials are placed behind the dilution holes to minimize the change on ventilation.

As indicated in Figure 1, the adsorbent materials tested were from commercial sources. Some of their physical properties are listed in Table 1. Also shown in Table 1 are the resistance to draw (RTD) and \% dilution of the prepared test cigarettes. These values compared favorably with the reference 1R4F cigarettes. On average, about $100 \mathrm{mg}$ of 20-60 mesh adsorbent materials were put into the PSP space except in the case of using smaller $35 \times 60$ silica gel granules, where only $77 \mathrm{mg}$ could be included to avoid high RTD.

\section{Analytical methods and procedures}

The samples were analyzed using the multiplex GC-MS method using Federal Trade Commission (FTC) parameters and procedures described in reference (1). In the procedure, multiple puffs of cigarette smoke were sequentially injected into a GC-MS system prior to the complete elution of the first injected puff. Relying on the chromatographic separation of the GC column and the spectroscopic separation of the MS detection system, the complex chromatographic data were reduced to meaningful puff-by-puff delivery results for each selected cigarette smoke constituent. The puff-by-puff delivery values, as shown in Figure 2 and Figure 3, were reported as percent vs. control for average total delivery of a $1 \mathrm{R} 4 \mathrm{~F}$ cigarette. 
a) Type I

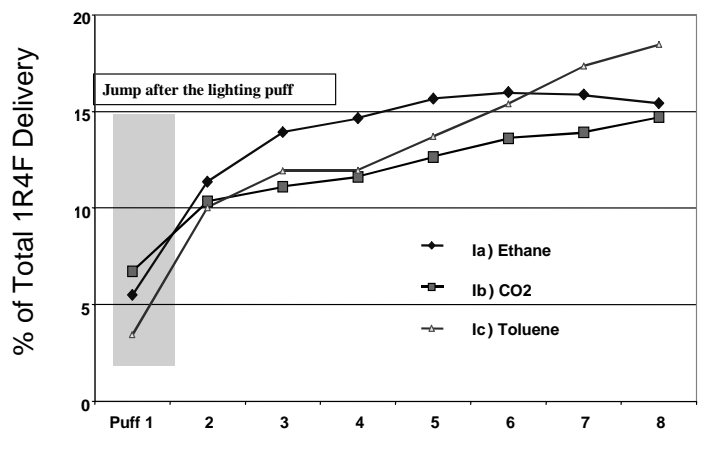

c) Type III

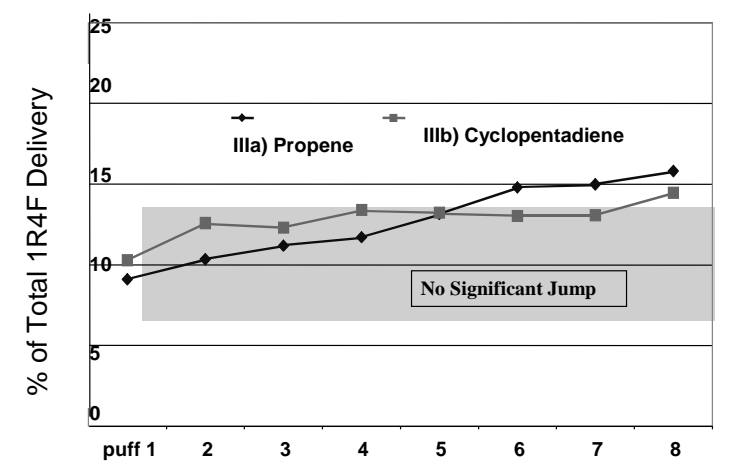

b) Type II

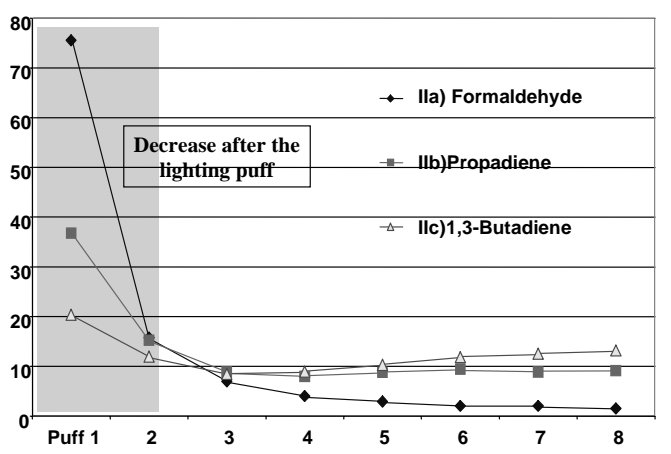

d) Type IV

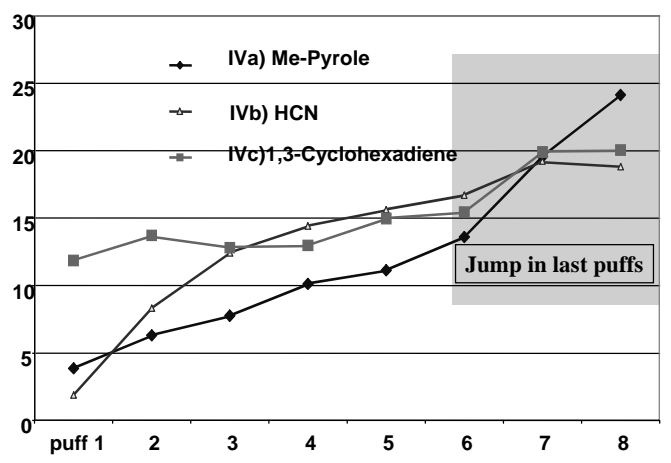

Figure 2. Type I-IV delivery profiles of gas-phase components in mainstream smoke of 1R4F cigarettes (average of 8 replicas)

\section{RESULTS AND DISCUSSION}

\section{Puff-by-puff delivery profiles}

Looking at the average puff-by-puff delivery values for the gas-phase components for $1 \mathrm{R} 4 \mathrm{~F}$ cigarettes, we have derived some typical delivery characteristics for each individual compound in the absence of adsorbent materials. Although the delivery behaviors of the components can be affected by many parameters including combustion chemistry, sampling methods, tobacco column packing, ventilation, and interaction with cellulose acetate plugs, four typical delivery behaviors were seen in the measured 26 compounds as shown in Figure 2. We have designated these four as Type I-IV profiles.

In a Type I profile, the components are delivered the least in the lighting puff, then increased in the second and succeeding puffs as shown in Figure 2a. The compounds in this category are ethane, diacetyl, carbon dioxide, toluene, hydrogen cyanide, carbonyl sulfide, hydrogen sulfide, 2,5dimethyl furan, methyl furan, methyl ethyl ketone, and cyclopentanone.

The Type II profile is just opposite to Type I. The components were delivered most in the lighting puffs, and significantly decreased in the second and succeeding puffs as shown in Figure 2b. The compounds in this category are formaldehyde, propadiene, and 1,3-butadiene.

Compounds with Type III profiles tend not to show any abrupt change in deliveries during the whole smoking dura- tion. Some gradual increase in deliveries may be observed from first puff to the eighth puff, due to changes in ventilation ratios and diffusion through the cigarette paper. The compounds in this category are propene, cyclopentadiene, methyl cyclopentadiene, acetaldehyde, acrolein, and benzene.

Compounds with Type IV delivery profiles rapidly increased in deliveries in last few puffs. Generally, there was a significant jump up in deliveries in last 2 to 3 puffs. The compounds in this category are methyl pyrrole, acetone, methyl mercaptan, acrylonitrile, isoprene, and 1,3-cyclohexadiene.

\section{Puff-by-puff reduction by solid adsorbents}

In PSP filters containing activated carbon, silica gel or polyaromatic resins, there are different levels of reduction for gas-phase compounds depending on the adsorbent used. Figure 3 shows the puff-by-puff filtration of selected gasphase compounds by the PSP filters with adsorbents. The PSP filter with activated carbon was most efficient at removing all the gas-phase compounds. Its filtration performance is superior to both silica gel and XAD-16 resin. The filtration performance of silica gel and XAD-16 polyaromatic resin varied with the chemical nature of the individual components as discussed in following sections.

As shown in Figure 3, Ia and $\mathbf{I b}$, both diacetyl and toluene exhibit Type I delivery profiles in the control 1R4F 
la) Diacetyl

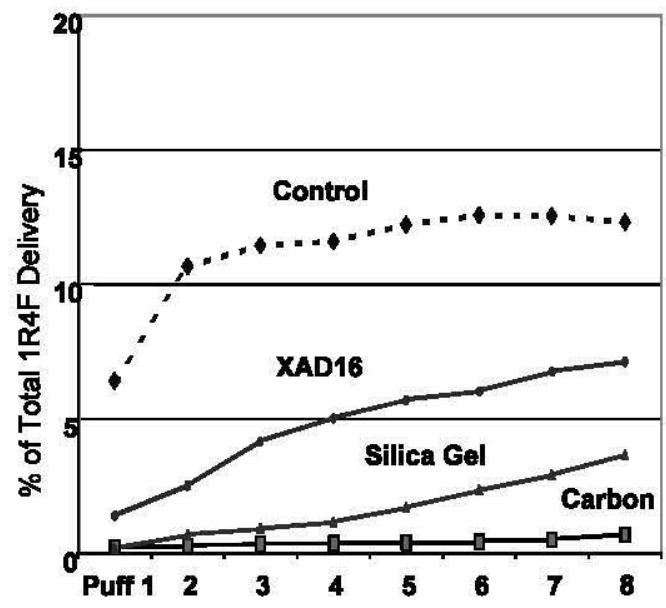

lla) Formaldehyde

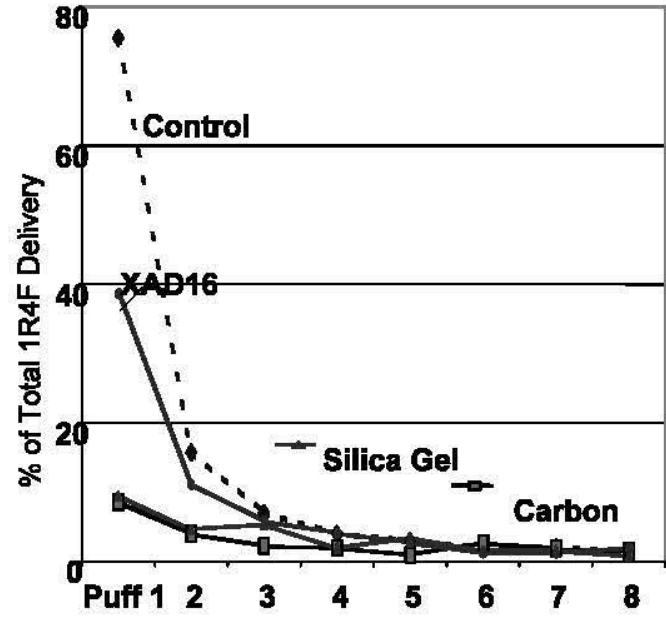

Illa) Acetaldehyde

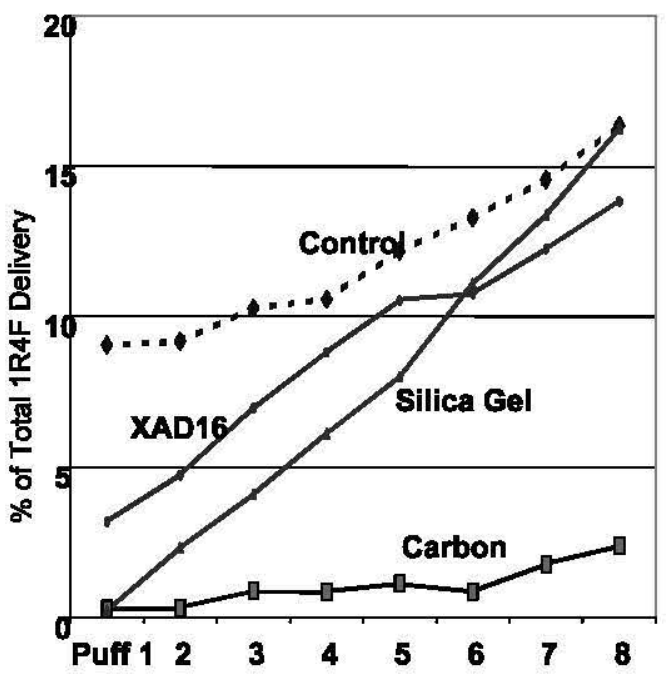

Ib) Toluene

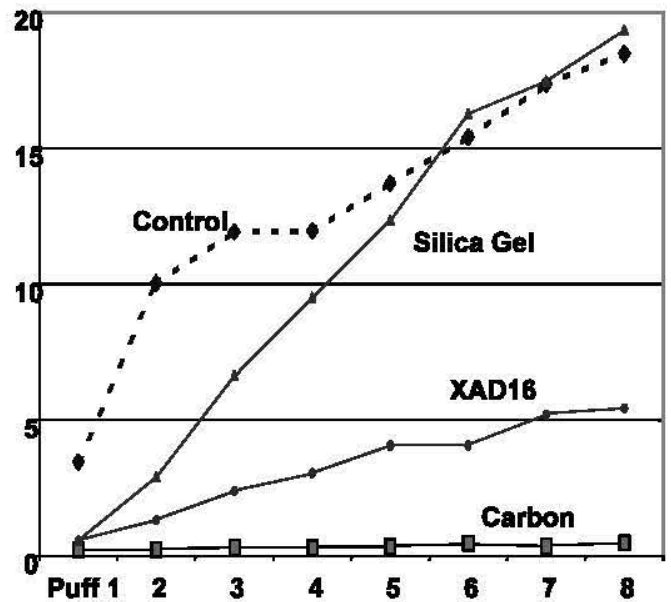

Ilb) 1,3Butadiene

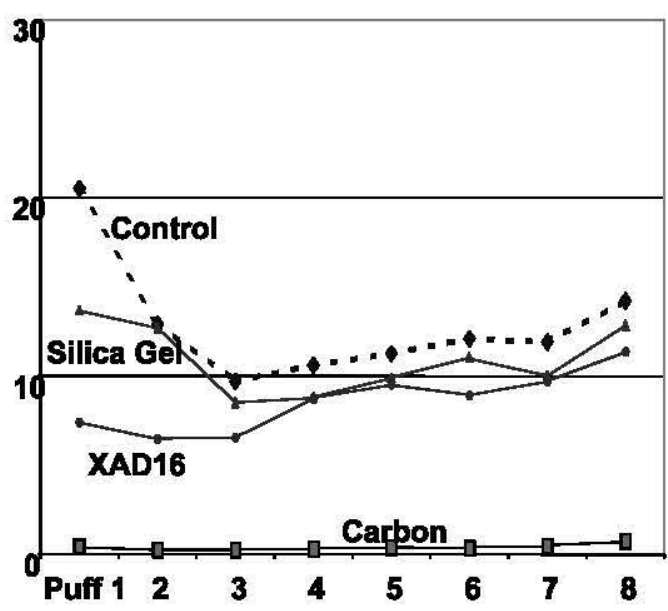

IIIb) Acrolein

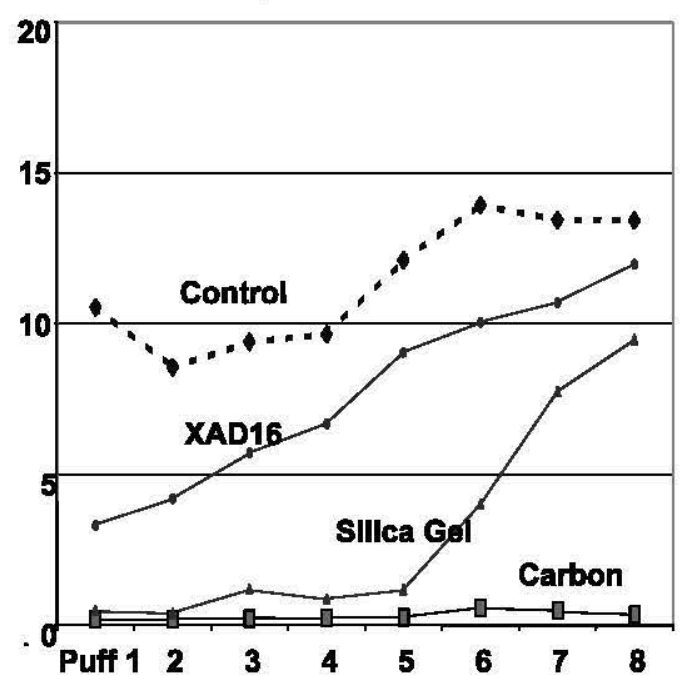

Figure 3. Effects of PSP adsorbent filters on the puff-by-puff delivery profiles of representative gas-phase components 
IVa) 1-Methyl Pyrrole

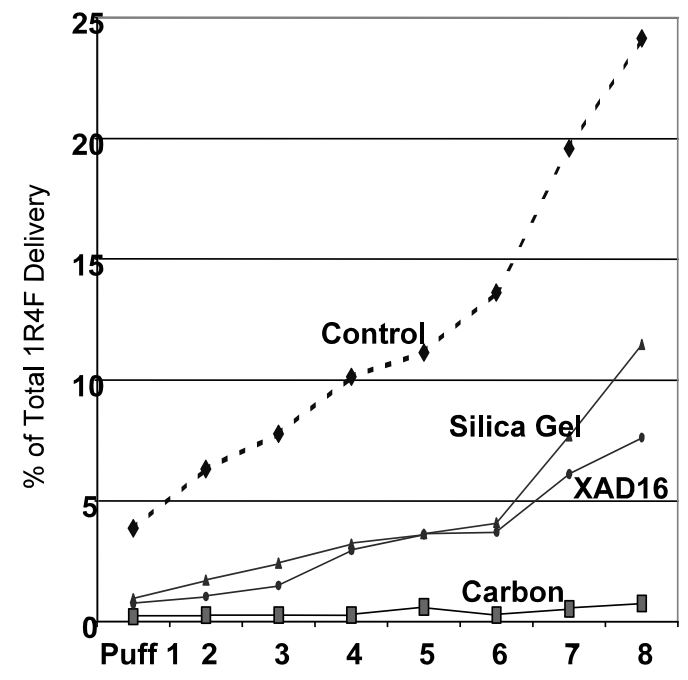

IVb) Isoprene

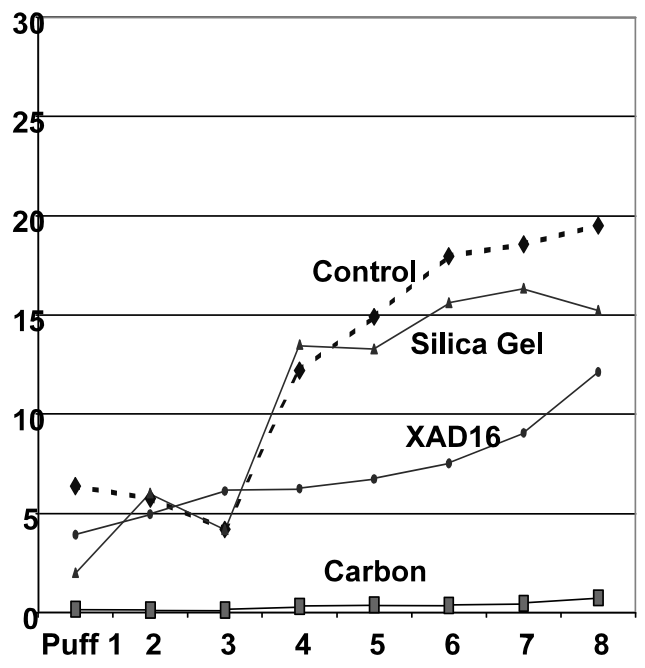

Figure 3 (contd.)

cigarettes. Toluene also exhibits some Type IV delivery profile characteristics. In comparison, XAD-16 resin was more efficient at removing toluene than silica gel, but silica gel was more efficient at removing the more polar diacetyl. For toluene, the silica gel removed $\sim 75 \%$ in the first two puffs, but quickly lost this activity by the fourth puff. XAD16 resin had about the same initial removal efficiency for toluene as the silica gel, but maintained its efficiency throughout the succeeding puffs.

Figure 3, IIa and IIb, shows that the puff-by-puff delivery of formaldehyde and 1,3-butadiene of 1R4F cigarettes exhibited Type II profiles. In comparing PSP filters containing silica gel and XAD-16 resin, the silica gel was more efficient at removing the polar formaldehyde, while XAD16 resin was better at removing 1,3-butadiene.

In Figure 3, IIIa and IIIb, both acetaldehyde and acrolein exhibited Type III delivery profiles in the control 1R4F cigarettes. Similar results were obtained for acetaldehyde and acrolein removal rates by PSP silica gel and XAD-16 filters. In both cases, silica gel is more effective in removing compounds with polar aldehyde groups. A greater difference is shown in the case of acrolein, where silica gel at its 70-mg loading in the PSP filter maintained $~ 90 \%$ removal until the fifth puff, while XAD-16 resin at its 100mg loading level had only $20 \%$ removal activity left at this puff.

In Figure 3, IVa and IVb, 1-methyl pyrrole and isoprene exhibited Type IV delivery profiles in the control 1R4F cigarettes. PSP filters with both XAD-16 resin and silica gel had comparable removals for 1-methyl pyrrole. However, only XAD-16 had an effect on isoprene delivery. Toward a polar aromatic molecular such as 1-methyl pyrrole, XAD polyaromatic resin may interact with its aromatic ring via $\pi-\pi$ interaction while silica gel may interact with its $\mathrm{N}$ atom by hydrogen bonding. The activity of $\mathrm{XAD}$ resin for isoprene may also come from $\pi-\pi$ interactions.

\section{Comparisons for absorbents using reduction in total deliveries}

In addition to comparisons of puff-by-puff delivery data, the filtration performances of adsorbents were also compared using the total gas-phase component deliveries per cigarette. By comparison with $1 \mathrm{R} 4 \mathrm{~F}$ total deliveries, the total percent reduction for each gas-phase compound measured due to the filtration by each particular absorbent can be determined. The percent reduction data are summarized in Table 2. Each of the percent reduction values was statistically evaluated, and if a significant percent reduction of a particular gas-phase compound was noted, that amount of reduction is shown in Table 2. If the percent reduction was deemed insignificant (smaller than $30 \%$ and 3 RSD), it is shown as a blank.

Activated carbon significantly reduces all of the gas-phase components observed except $\mathrm{CO}_{2}$ and ethane. These results are expected since the activated carbon has high surface area $\left(1590 \mathrm{~m}^{2} / \mathrm{g}\right)$ and diversified surface activity (5). In comparison, the silica gel, although it has much lower surface area $\left(275-375 \mathrm{~m}^{2} / \mathrm{g}\right)$, still shows significant reduction for polar compounds such as aldehydes, acrolein, ketones and pyrroles. All of the gas-phase compounds reduced by silica gel have, in common, hydrogen-bondable $\mathrm{O}$ or $\mathrm{N}$ atoms. Its filtration performance for these compounds is most likely the result of hydrogen bonding between $\mathrm{Si}-\mathrm{OH}$ and $\mathrm{O}$ or $\mathrm{N}$ atoms with lone electron pairs. However, the mechanism of adsorption of these polar compounds onto the surface of silica gel still needs further investigation. Looking at the XAD-16 resin, it has a higher surface area $\left(800 \mathrm{~m}^{2} / \mathrm{g}\right)$ than the silica gel, and exhibits adsorbent activity for not only aromatic compounds such as benzene, toluene and furans, but also for cyclic dienes such as 1,3-cyclopentadiene and methyl pentadiene, and ketones such as acetone, methyl ethyl ketone and cyclopentanone. Its filtration performance to these classes of 
Table 2. Effects of PSP adsorbent filters on the total delivery of mainstream gas-phase compounds in $1 \mathrm{R} 4 \mathrm{~F}$ cigarettes ${ }^{\mathrm{a}}$

\begin{tabular}{|c|c|c|c|c|}
\hline Compound & $\begin{array}{c}\text { Control/RSD } \\
(\%)\end{array}$ & $\begin{array}{c}\text { Carbon } \\
(\%)\end{array}$ & $\begin{array}{c}\text { Silicia gel } \\
(\%)\end{array}$ & $\begin{array}{c}\text { XAD-16 } \\
(\%)\end{array}$ \\
\hline Carbon dioxide & 6 & & & \\
\hline Propene & 8 & -80 & & \\
\hline Hydrogen cyanide & 17 & -90 & & \\
\hline Ethane & 8 & & & \\
\hline Propadiene & 13 & -70 & & -40 \\
\hline 1,3-Butadiene & 10 & -95 & & -35 \\
\hline Isoprene & 9 & -95 & & -40 \\
\hline Cyclopentadiene & 9 & -95 & & -40 \\
\hline $\begin{array}{l}\text { 1,3-Cyclohexa- } \\
\text { diene }\end{array}$ & 10 & -95 & & -65 \\
\hline $\begin{array}{l}\text { Methyl cyclopenta- } \\
\text { diene }\end{array}$ & 9 & -95 & & -60 \\
\hline Formaldehyde & 24 & -80 & -70 & -35 \\
\hline Acetaldehyde & 8 & -90 & -40 & -30 \\
\hline Acrolein & 14 & -95 & -70 & -35 \\
\hline Acetone & 9 & -95 & -90 & -40 \\
\hline Diacetyl & 12 & -95 & -80 & -60 \\
\hline Methyl ethyl ketone & 9 & -95 & -90 & -40 \\
\hline Cyclopentanone & 9 & -95 & -60 & -75 \\
\hline Benzene & 9 & -95 & & -60 \\
\hline Toluene & 9 & -95 & & -70 \\
\hline Acrylonitrile & 21 & -90 & -40 & -55 \\
\hline Methyl furan & 7 & -95 & & -50 \\
\hline 2,5-Dimethyl furan & 8 & -95 & & -65 \\
\hline Hydrogen sulfide & 16 & -95 & & \\
\hline Carbonyl sulfide & 10 & -85 & & \\
\hline Methyl mercaptan & 11 & -80 & & \\
\hline 1-Methyl pyrrole & 10 & -95 & -65 & -75 \\
\hline
\end{tabular}

${ }^{a}$ Bold number mean the \% reduction value is statistically significant ( $\geq 3 \mathrm{RSD}$ ), regular non-bold number means the \% reduction value was marginal ( $<3 \mathrm{RSD}$, but $\geq 30 \%$ ), and blank means the $\%$ reduction value is not statistically significant ( $<3 \mathrm{RSD}$ and $30 \%)$.

compounds may be the result of $\pi-\pi$ molecular orbital (MO) interaction between the aromatic systems in the polyaromatic resins and the double bond systems in the adsorbates.

\section{CONCLUSION}

Using the multiplex GC-MS method, we have evaluated the puff-by-puff filtration performance of activated carbon, silica gel and polyaromatic XAD-16 resin for 26 mainstream smoke gas-phase components. Four types of puffby-puff gas component delivery profiles were observed in mainstream smoke of 1R4F cigarettes. Activated carbon shows very high removing activity for all the gas-phase components measured except $\mathrm{CO}_{2}$ and ethane. This is due to its high surface area and diversified surface activity. Silica gel shows selective reducing activity for compounds with hydrogen-bondable atoms such as aldeydes, ketones, acrolein and pyrroles. XAD-16 resin showed varied levels of activity to aromatic compounds, cyclic dienes and ketones via potential $\pi-\pi$ molecular orbital interactions.

\section{REFERENCES}

1. Thomas, C.E. and K.B. Koller: Puff-by-puff mainstream smoke analyses by multiplex gas chromatography-mass spectrometry; Beitr. Tabakforsch. Int. 19 (2001) 345-351.

2. Fisher, B.: Unraveling smoke. Smoke chemistry: a series; Tob. Reporter, 129, No. 9, September 2000.

3. Browne, C.L.: The design of cigarettes; Celanese Acetate LLC., January 4, 2000.

4. George, T.W. and C.H. Keith: The selective filtration of tobacco smoke; in: Tobacco and tobacco smoke, edited by E. Wynder and D. Hoffmann, Academic Press, 1969, 577-609.

5. Figueiredo, J.L., M.F.R. Pereira, M.M.A. Freitas, and J.J.M. Orfao: Modification of the surface chemistry of activated carbons; Carbon 37 (1999) 1379-1389.

Address for correspondence:

Lixin Xue

Philip Morris USA, P.O, Box 26583

Richmond VA 23261

USA. 